\title{
La protección de la mujer trabajadora contra la discriminación
}

\section{Protection of the Working Woman against Discrimination}

\author{
Javier Arévalo Vela*
}

http://dx.doi.org/10.21503/lex.v15i19.1379

* Abogado y magíster en Derecho por la Universidad Nacional Mayor de San Marcos. Concluyó sus estudios doctorales en la misma universidad. Especialización en Derecho del Trabajo en la Escuela Judicial del Reino de España. Docente acreditado en Enseñanza del Derecho y Argumentación Jurídica por la Universidad de Alicante de España, con Posgrado en Derecho Constitucional y Gobierno y Gestión Judicial por la Universidad Carlos III de Madrid, España. Ha sido miembro de la Comisión que elaboró la Nueva Ley Procesal del Trabajo. Actualmente es juez supremo titular, presidente de la Segunda Sala de Derecho Constitucional y Social Transitoria de la Corte Suprema de Justicia de la República del Perú, encargada de la aplicación de la Nueva Ley Procesal del Trabajo. E-mail: arevalovela@yahoo.es






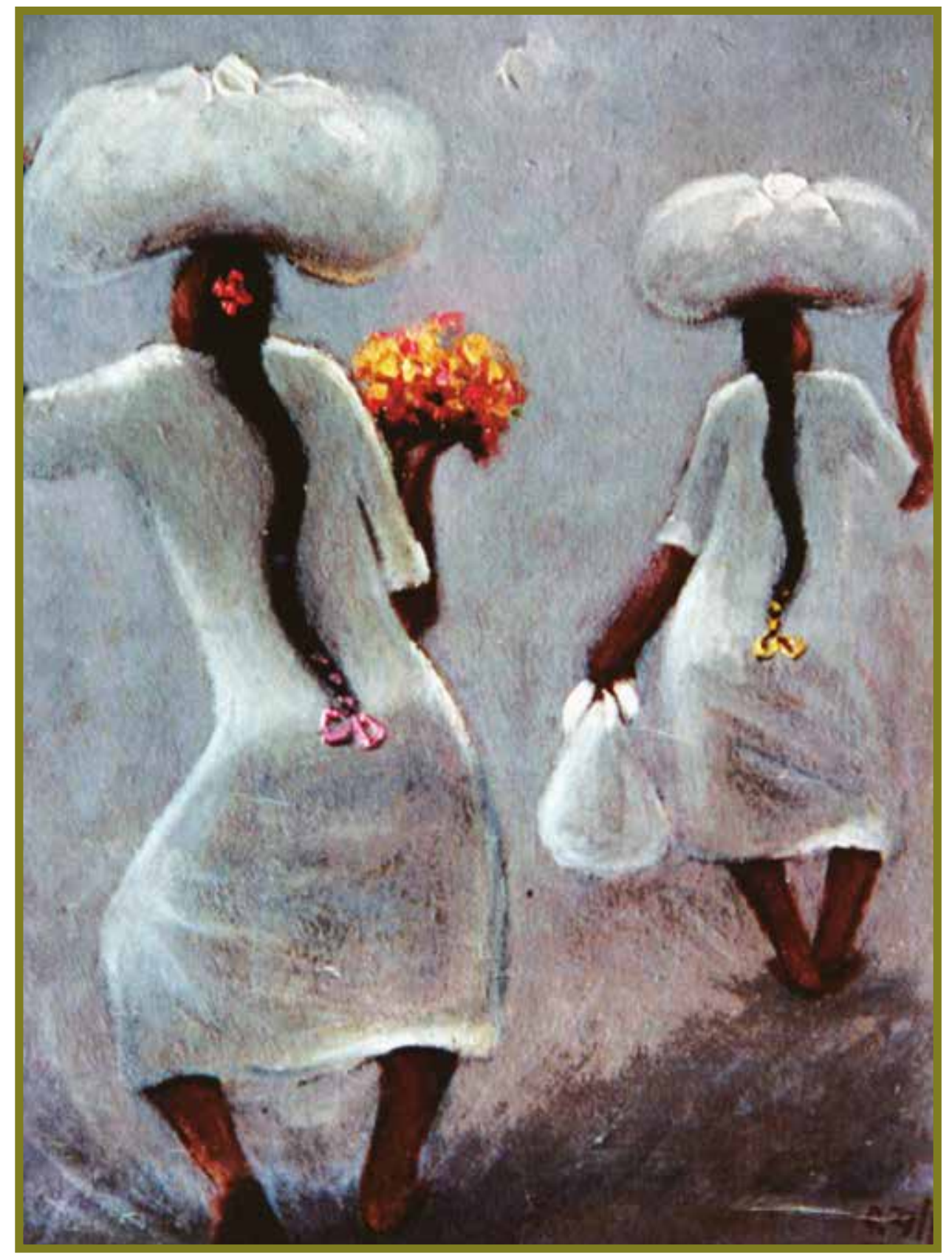

Lavanderas. Óscar Allaín 


\section{RESUMEN}

En el presente artículo se aborda el tema de la protección de la mujer trabajadora contra la discriminación, realizando un breve comentario sobre la legislación que proscribe tales actos dentro de nuestro ordenamiento jurídico laboral.

Palabras clave: discriminación, protección de la mujer trabajadora.

\section{ABSTRACT}

This paper addresses the protection of the working woman against discrimination, through brief comments about the body of laws that prohibits such acts within our labor legal system.

Key words: discrimination; protection of the working woman. 


\section{INTRODUCCIÓN}

La discriminación de la mujer constituye un problema de actualidad que merece atención especial por parte del Derecho del Trabajo, pues cada vez más mujeres se incorporan a la actividad productiva, y son víctimas de conductas discriminatorias en diversas modalidades.

En el Perú, el inciso 2) del artículo $2^{\circ}$ de la Constitución de 1993 consagra el derecho fundamental de toda persona a la igualdad ante la ley, repudiando toda forma de discriminación basada en el origen, sexo, idioma, religión, opinión, condición económica o de cualquier otra índole.

Nuestra Carta Magna no hace referencia expresa a la mujer trabajadora como sujeto de especial protección por razón de su sexo, sino que su artículo $22^{\circ}$ ha considerado su protección a partir de que se encuentre en estado de maternidad (consideración subjetiva); sin embargo, esta situación no es obstáculo para que se genere una protección especial para las mujeres que trabajan, en aplicación de los instrumentos internacionales suscritos por el Perú.

Para entender en qué consiste la discriminación, primero debemos saber qué es el derecho a la igualdad.

El Tribunal Constitucional ha explicado cómo debe ser entendido el derecho a la igualdad en los términos siguientes: "Contrariamente a lo que pudiera desprenderse de una interpretación literal, se trata de un derecho fundamental que no consiste en la facultad de las personas para exigir un trato igual a los demás, sino por ser tratadas del mismo modo que quienes se encuentren en idéntica situación". ${ }^{1}$

En cuanto al contenido esencial del derecho a la igualdad, el máximo intérprete de la Constitución expresa:

1 STC N 01008-2013-PA/TC del 8 de agosto de 2014, Caso Bayona Vilela, fundamento 3.2.1. 
(...) el contenido esencial del derecho a la igualdad tiene dos facetas: igualdad en la ley e igualdad ante la ley. La igualdad en la ley implica que un mismo órgano no puede modificar arbitrariamente el sentido de sus decisiones en casos sustancialmente iguales, y que cuando el órgano en cuestión considere que debe apartarse de sus precedentes, tiene que ofrecer para ello una fundamentación suficiente y razonable. En cuanto a la igualdad ante la ley, la norma debe ser aplicable por igual a todos los que se encuentren en la situación descrita en el supuesto de la norma. ${ }^{2}$

De las citas presentadas se puede concluir que ninguna persona merece ser tratada de una manera diferente a otra que, de acuerdo al ordenamiento jurídico, se encuentre en idéntica situación a ella.

Contrario al concepto de igualdad aparece el de discriminación, entendida esta como un trato diferente, totalmente injustificado, que desconoce la igualdad entre las personas, a partir de causas especialmente cuestionables, que niegan considerar iguales a los seres humanos aun cuando se encuentren en idéntica situación.

Precisando cuándo debemos entender que estamos frente a un caso de discriminación, el propio Tribunal Constitucional ha señalado: "Sin embargo, se debe tener en cuenta que no toda desigualdad constituye necesariamente discriminación: la igualdad solamente será vulnerada cuando el trato desigual carezca de una justificación objetiva y razonable" ${ }^{3}$

\section{LA DISCRIMINACIÓN EN MATERIA LABORAL}

El autor nacional Blancas Bustamante respecto a la discriminación nos dice lo siguiente:

La discriminación, con ser un fenómeno social, se caracteriza y concretiza por sus manifestaciones jurídicas, ya que se traduce en la privación al individuo o grupo discriminado del goce pleno de sus derechos, tanto fundamentales como meramente legales. El sujeto - individual o colectivo - objeto de discriminación se ve privado de disfrutar de los derechos que todos los ciudadanos gozan y, por consiguiente, su estatus jurídico real dentro de la sociedad se caracteriza por la minusvalía jurídica.

La trascendencia de esta grave situación para la sociedad lleva al ordenamiento jurídico no solo a rechazar la discriminación, sino a admitir la validez de la diferenciación de trato cuando esta tenga por objeto superar dicha situación, para lograr la igualdad real de los grupos postergados. ${ }^{4}$

\footnotetext{
STC N ${ }^{\circ}$ 01008-2013-PA/TC del 8 de agosto de 2014, Caso Bayona Vilela, fundamento 3.2.2. STC N ${ }^{\circ}$ 01008-2013-PA/TC del 8 de agosto de 2014, Caso Bayona Vilela, fundamento 3.2.2.

4 Carlos Blancas Bustamante, Derechos fundamentales de la persona y relación de trabajo, primera edición (Lima: Fondo Editorial de la Pontificia Universidad Católica del Perú, 2007), 153-154.
} 
Por nuestra parte consideramos que por discriminación podemos entender todo acto tendiente a establecer una diferenciación injustificada entre personas que se encuentran en la misma condición, originando un perjuicio o una disminución en los derechos sean fundamentales o de origen legal del sujeto objeto de tal acto lesivo, impidiendo su realización como persona y poniéndolo en una situación de desventaja frente a sus pares.

La discriminación por razón de sexo se presenta con mucha frecuencia en el ámbito de las relaciones de trabajo. Sobre esta conducta repudiable el Tribunal Constitucional nos dice lo siguiente:

36. La discriminación en el entorno laboral es un fenómeno social cotidiano y universal que provoca desigualdades entre las personas y genera desventajas sociales y económicas que debilitan la cohesión y la solidaridad sociales. Por ello, la erradicación de la discriminación laboral tiene por finalidad promover la igualdad de oportunidades a fin de que tanto hombres como mujeres disfruten de un trabajo decente, sin perjuicio de su origen, sexo, raza, color, orientación sexual, religión, opinión, condición económica, social, idioma, o de cualquier otra índole.

37. En este contexto, la discriminación laboral se produce cada vez que se escoge o rechaza a un trabajador por razón de su origen, sexo, raza, color, orientación sexual, religión, opinión, condición económica, social, idioma o de cualquier otra índole. En buena cuenta, la discriminación en el entorno laboral supone dispensar un trato distinto a las personas atendiendo a ciertas características, como pueden ser la raza, el color o el sexo, lo cual entraña un menoscabo del derecho a la igualdad de oportunidades y de trato y a la libertad de trabajo, debido a que la libertad del ser humano para elegir y desarrollar sus aspiraciones profesionales y personales se ve restringida. ${ }^{5}$

\section{CLASES DE DISCRIMINACIÓN EN MATERIA LABORAL}

Como sabemos, la discriminación en el trabajo puede presentarse en el acceso, durante el desarrollo de la relación laboral o a su término. Durante el acceso al empleo se materializa la discriminación cuando se establecen determinados requisitos para acceder a un puesto que no se encuentran sustentados en la capacidad ni experiencia del trabajador, tal como sería el hecho de que una empresa requiriese para el cargo de secretaria solo la presencia de mujeres de tez blanca; de donde se advierte evidentemente un trato discriminatorio o desigual con el resto de mujeres que por capacidad podrían desempeñar correctamente dicha labor.

Por otra parte, la discriminación durante el desarrollo de la relación laboral se puede manifestar de múltiples formas, siendo una de las más comunes el trato diferenciado y perjudicial que reciben aquellos trabajadores que optan por afiliarse a un sindicato de la empresa,

5 STC Nº 05652-2007-PA/TC del 06 de noviembre de 2008, Caso Rosa Bethzabé Gambini Vidal, fundamentos 36 y 37. 
los cuales son hostilizados por parte del empleador o de sus representantes por ese simple hecho.

Finalmente, la discriminación al término de la relación de trabajo se origina por el despido nulo, cuando este se encuentra basado en el sexo, raza, religión, opinión, idioma, discapacidad o de cualquier otra índole. Dicha clase de despido se encuentra tipificada en el literal d) del artículo $29^{\circ}$ del Decreto Supremo N $^{\circ}$ 003-97-TR, Texto Único Ordenado del Decreto Legislativo $\mathrm{N}^{\circ} 728$, Ley de Productividad y Competitividad Laboral, publicado en el Diario Oficial El Peruano el 27 de marzo de 1997, y es sancionado con la reposición del trabajador al puesto en el cual se venía desempeñando antes de producido el acto lesivo.

Asimismo, de acuerdo con la doctrina y la jurisprudencia, la discriminación laboral puede ser de dos clases: directa o indirecta.

En materia laboral, el Tribunal Constitucional reconoce las clases de discriminación siguientes:

42. La discriminación laboral puede manifestarse cuando se busca un trabajo, en el empleo $\mathrm{o}$ al dejar este. Las personas pueden ser excluidas o incluso disuadidas de aspirar a un empleo por motivos de raza, sexo, religión u orientación sexual, entre otros motivos, o pueden ser obstaculizadas para ser promovidas profesionalmente. Por ejemplo, hay discriminación laboral cuando a una persona profesionalmente calificada, pero miembro de un grupo político minoritario, se le deniega un empleo, o cuando trabajadores competentes son víctimas de acoso laboral por motivo de su afiliación sindical.

43. Sin embargo, no todas las distinciones de trato han de considerarse discriminatorias. Según el Art. 1.2 del Convenio 111, un trato diferenciado que tenga su origen en las cualificaciones exigidas para un puesto de trabajo es una práctica perfectamente legítima. Por lo tanto, en este contexto, mientras no se restrinja la igualdad de oportunidades, las diferencias de trato no se considerarán discriminatorias.

Asimismo, entre las medidas que no constituyen discriminación laboral cabe mencionar aquellas destinadas a salvaguardar la seguridad del Estado y las motivadas por imperativos especiales de protección, esto es, aquellas dirigidas a atender necesidades específicas en el ámbito de la salud de hombres o mujeres.

Tampoco son discriminatorias las medidas especiales que conllevan un trato diferenciado para quienes tienen necesidades particulares por razones de género, o de discapacidad mental, sensorial o física.

44. La discriminación en el trabajo puede ser directa o indirecta. Es directa cuando las normas jurídicas, las políticas y los actos del empleador excluyen, desfavorecen o dan preferencia explícitamente a ciertos trabajadores atendiendo a características como la opinión polí- 
tica, el estado civil, el sexo, la nacionalidad, el color de la piel o la orientación sexual, entre otros motivos, sin tomar en cuenta sus cualificaciones y experiencia laboral. Por ejemplo, los anuncios de ofertas de empleo en los que se excluyen a los aspirantes mayores de cierta edad, o de determinado color de piel o complexión física, es una forma de discriminación directa.

45. En cambio, la discriminación es indirecta cuando ciertas normas jurídicas, políticas y actos del empleador de carácter aparentemente imparcial o neutro tienen efectos desproporcionadamente perjudiciales en gran número de integrantes de un colectivo determinado, sin justificación alguna e independientemente de que estos cumplan o no los requisitos exigidos para ocupar el puesto de trabajo de que se trate, pues la aplicación de una misma condición, un mismo trato o una misma exigencia no se les exige a todos por igual. Por ejemplo, el supeditar la obtención de un puesto de trabajo al dominio de un idioma en particular cuando la capacidad lingüística no es requisito indispensable para su desempeño es una forma de discriminación indirecta por razón de la nacionalidad o la etnia de origen.

También puede haber discriminación indirecta cuando se dispensa un trato diferenciado a categorías específicas de trabajadores, traducida en menores prestaciones sociales o remuneraciones, siempre que este no se realice sobre bases objetivas y razonables. ${ }^{6}$

Conforme a lo expresado, podemos decir que la discriminación directa se manifiesta cuando mediante una norma legal o un acto del empleador se establece un trato diferenciado o desventajoso entre dos o más trabajadores que se encuentran en la misma condición, es decir, sin que medie una causa objetiva para la existencia de dicho actuar perjudicial; mientras que la discriminación indirecta se presenta cuando una norma jurídica o conducta del empleador, aparentemente neutral o revestida de legalidad, produce diferenciaciones entre trabajadores, las cuales generan perjuicios en un grupo determinado de aquellos.

Según Jaime Martínez, al referirse al origen de la discriminación indirecta:

A partir del caso Griggs vs. Duke Power Corp de 1971, en el cual la Suprema Corte de los Estados Unidos hizo una interpretación del Título VII de la Civil Rights Act de 1994, se ha venido admitiendo el concepto de "discriminaciones indirectas", considerando como tales aquellas prácticas que, siendo neutras en el tratamiento de los diferentes grupos, sin embargo no encuentran una justificación en una exigencia de la organización de la empresa (business necessity) y desfavorecen a algunos grupos (mujeres), en palabras de la misma sentencia: "son conductas formalmente lícitas, pero con efectos discriminatorios". El concepto de discriminación indirecta ha sido acogido por otros altos tribunales, como la Suprema Corte de Canadá y, sobre todo, por el Tribunal de Justicia de la Comunidad Europea, con gran influencia en los tribunales europeos. ${ }^{7}$

6 STC N 05652-2007-AA, del 06 de noviembre de 2008, caso Rosa Bethzabé Gambini Vidal, fundamentos 34 a 46.

7 Héctor Armando Jaime Martínez, "Los derechos fundamentales de la persona del trabajador", en: Ensayos sobre Derecho del Trabajo y Derecho de la Seguridad Social, Colección de Estudios Jurídicos Nº 19 (Caracas, 2008), 449. 
$\mathrm{Al}$ respecto, el Tribunal Constitucional ha dicho lo siguiente:

21. El derecho fundamental a no ser discriminado por razón de sexo (...) incluye dos mandatos. El primero es la prohibición de discriminación directa, a través de la cual toda norma que dispense un trato diferente y perjudicial en función de la pertenencia a uno u otro sexo es inconstitucional, lo que comporta la obligación de exigir un trato jurídico indiferenciado para hombres y mujeres como regla general. El segundo es la prohibición de la discriminación indirecta, es decir, de aquellos tratamientos jurídicos formalmente neutros, pero de los cuales se derivan consecuencias desiguales y perjudiciales por el impacto diferenciado y desfavorable que tiene sobre los miembros de uno u otro sexo.

22. De este modo, en el caso de las mujeres la prohibición de discriminación por razón de sexo tiene su razón de ser en la necesidad de terminar con la histórica situación de inferioridad de la mujer en la vida social, cultural, económica y política. Por ello, para asegurar la igualdad real de la mujer en los diferentes entornos sociales, se ha previsto la prohibición de todo tipo discriminación por razón de sexo.

23. La discriminación por razón de sexo comprende aquellos tratamientos peyorativos que se fundan no solo en la pura y simple constatación del sexo de la víctima, sino también en la concurrencia de razones o circunstancias que tengan con el sexo de la persona una conexión directa e inequívoca. Tal sucede con el embarazo, elemento o factor diferencial que, por razones obvias, incide de forma exclusiva sobre las mujeres. Las decisiones extintivas basadas en el embarazo, al afectar exclusivamente a la mujer, constituyen, indudablemente, una discriminación por razón de sexo proscrita por el inciso 2 del artículo 2 de nuestra Constitución.

24. En tal sentido, la protección de la mujer no se limita a la de su condición biológica durante el embarazo y después de este, ni a las relaciones entre la madre y el hijo durante el período que sigue al embarazo y al parto, sino también se extiende al ámbito estricto del desarrollo y a las vicisitudes de los distintos tipos de relaciones que se pueden entablar en una sociedad: educativa, laboral, entre otras. ${ }^{8}$

\section{LEGISLACIÓN SOBRE ACTOS DISCRIMINATORIOS}

\section{a) Código Civil}

De acuerdo con lo establecido por el Código Civil vigente, aprobado por el Decreto Legislativo N ${ }^{\circ} 295$, publicado en el Diario Oficial El Peruano el 25 de julio de 1984, en su artículo $4^{\circ}$ establece la igualdad en el goce y ejercicio de los derechos civiles entre el varón y la mujer.

8 STC N ${ }^{\circ}$ 01423-2013-AA, del 09 de diciembre de 2015, caso Andrea Celeste Álvarez Villanueva, fundamentos 21 a 24. 


\section{b) Ley $\mathrm{N}^{\circ} 26772$}

La Ley No 26772, publicada en el Diario Oficial El Peruano el 17 de abril de 1997, modificada por la Ley $\mathrm{N}^{\circ} 27270$, publicada el 29 de mayo del 2000, prohíbe que en toda oferta de empleo o de acceso a centros de formación educativa se establezcan requisitos que constituyan discriminación, anulación o alteración de la igualdad de trato (artículo $1^{\circ}$ ).

Asimismo, precisa que debe entenderse como discriminación la anulación o alteración de la igualdad de oportunidades o de trato, en los requerimientos de personal, a los requisitos para acceder a centros de educación, formación técnica y profesional, que impliquen un trato diferenciado basado en motivos de raza, sexo, religión, opinión, origen social, condición económica, estado civil, edad o cualquier otra índole (artículo $2^{\circ}$ ).

Por otra parte, dispone la sanción pertinente a las personas naturales o jurídicas que en el ejercicio de su actividad, a través de sus funcionarios o dependencias, incurran en actos de discriminación, anulación o alteración de igualdad de oportunidades o de trato, estableciendo como ente competente para aplicar dicha sanción al Ministerio de Trabajo y Promoción del Empleo, si dichas conductas se encuentran referidas a ofertas de empleo. Para el caso de las conductas referidas al acceso a centros de formación educativa, la entidad competente para aplicar las sanciones será el Ministerio de Educación (artículo $3^{\circ}$ ).

\section{c) El Decreto Supremo $\mathrm{N}^{\circ}$ 002-98-TR}

El Decreto Supremo No 002-98-TR, norma reglamentaria de la Ley No 26772, publicado en el Diario Oficial El Peruano el 01 de febrero de 1998, precisa que la prohibición contenida en el artículo $1^{\circ}$ de dicha Ley es aplicable a los empleadores contratantes, a los medios de formación educativa, así como agencias de empleo y otros que sirven de intermediadores en las ofertas de trabajo $\left(\right.$ artículo $1^{\circ}$ ).

Por otra parte, la norma reglamentaria citada dispone la obligación de los medios de comunicación de colaborar con la Autoridad Administrativa de Trabajo en las investigaciones que efectúe respecto de denuncias por actos de discriminación en las ofertas de empleo (artículo $2^{\circ}$ ).

Asimismo, el reglamento define los casos en los cuales las diferencias no se considerarán discriminatorias, por encontrarse sustentadas en una justificación objetiva y razonable, aquellas basadas en las calificaciones exigidas para el desempeño del empleo o medio de formación ofertado (artículo $3^{\circ}$ ).

No constituyen justificaciones objetivas y razonables; por lo tanto, de suceder este tipo de hechos serán considerados discriminatorios aquellos referidos a las preferencias subjetivas de los clientes, o a los costos específicos derivados de la contratación o admisión de una persona. 
Tampoco se considera que exista una justificación objetiva y razonable cuando se excluye al postulante en función de su pertenencia a un grupo, gremio o asociación con fines lícitos (artículo $4^{\circ}$ ).

Finalmente, la norma reglamentaria objeto de comentario determina la facultad de la Autoridad Administrativa de Trabajo para investigar a pedido de parte, o excepcionalmente de oficio, los casos de discriminación en las ofertas de empleo (artículo $5^{\circ}$ ).

\section{d) Ley $\mathrm{N}^{\circ} 28983$}

La Ley $\mathrm{N}^{\circ} 28983$, Ley de igualdad de oportunidades entre mujeres y hombres, publicada en el Diario Oficial El Peruano el 16 de marzo de 2007, establece un marco normativo, institucional y de políticas públicas con el objeto de garantizar el pleno ejercicio de los hombres y mujeres de los derechos a la igualdad, dignidad, libre desarrollo, bienestar y autonomía, impidiendo la discriminación en todas las esferas de su vida pública y privada, propendiendo a la plena igualdad $\left(\right.$ artículo $\left.1^{\circ}\right)$.

De acuerdo con la Ley, se considera discriminación cualquier tipo de distinción, exclusión o restricción basada en el sexo que tenga por objeto o por resultado menoscabar o anular el reconocimiento, goce o ejercicio de los derechos de las personas independientemente de su estado civil, sobre la base de la igualdad entre la mujer y el hombre, de los derechos humanos y las libertades fundamentales en las esferas política, económica, social, cultural o en cualquier otra, en concordancia con lo establecido en la Constitución Política del Perú y en los instrumentos internacionales ratificados por el Estado peruano (artículo $2^{\circ}$ ).

La Ley se basa en los principios fundamentales de igualdad, respeto por la libertad, dignidad, seguridad, vida humana, así como el reconocimiento del carácter pluricultural y multilingüe de la nación peruana (numeral 3.1 del artículo $3^{\circ}$ ).

La Ley asigna al Estado la labor de impulsar la igualdad de oportunidades entre hombres y mujeres, considerando los principios que ella señala (numeral 3.2 del artículo $3^{\circ}$ ).

Conforme a lo previsto en la referida Ley, el Estado es el encargado de promover y garantizar la igualdad de oportunidades entre mujeres y hombres, tomando para dicho fin las medidas que resulten necesarias a efectos de remover los obstáculos que impiden el ejercicio de este derecho fundamental, así como erradicar toda conducta discriminatoria que tenga como sustento la condición sexual (numeral 1 del artículo $4^{\circ}$ ).

Respecto al cumplimiento de la Ley $\mathrm{N}^{\circ}$ 28983, el propio dispositivo señala los lineamientos del Poder Legislativo (artículo $5^{\circ}$ ), los lineamientos del Poder Ejecutivo, gobiernos regionales y locales (artículo $6^{\circ}$ ), Poder Judicial y del Sistema de Administración de Justicia $\left(\right.$ artículo $7^{\circ}$ ), organismos constitucionalmente autónomos (artículo $8^{\circ}$ ). 
La Ley señala como órgano rector del tema de igualdad de oportunidades para la mujer al Ministerio de la Mujer y Desarrollo Social (literal a del artículo $9^{\circ}$ ); asimismo, establece que la Presidencia del Consejo de Ministros (PCM) sustentará ante el Pleno del Congreso los avances en el cumplimiento de la referida norma (literal b del artículo $9^{\circ}$ ), así como corresponderá a la presidencia de los Gobiernos Regionales incluir los avances del cumplimiento del presente dispositivo normativo de acuerdo con lo previsto en la Ley Orgánica de Gobiernos Regionales.

Por otra parte, constituye un rol del Estado adoptar medidas de acción positiva de carácter temporal encaminadas a acelerar la igualdad de hecho entre la mujer y el hombre, las que no se considerarán discriminatorias; así como incorporar y promover el uso de lenguaje inclusivo (numerales 2 y 3 del artículo $4^{\circ}$ ).

\section{e) Decreto Legislativo $N^{\circ} 1323$}

El Decreto Legislativo $N^{\circ} 1323$, Decreto Legislativo que fortalece la lucha contra el feminicidio, la violencia familiar y la violencia de género, publicado en el Diario Oficial El Peruano el 6 de enero de 2017, se ha modificado el artículo 323 del Código Penal en los siguientes términos:

\section{Artículo 323.- Discriminación e incitación a la discriminación}

El que, por sí o mediante terceros, realiza actos de distinción, exclusión, restricción o preferencia que anulan o menoscaban el reconocimiento, goce o ejercicio de cualquier derecho de una persona o grupo de personas reconocido en la ley, la Constitución o en los tratados de derechos humanos de los cuales el Perú es parte, basados en motivos raciales, religiosos, nacionalidad, edad, sexo, orientación sexual, identidad de género, idioma, identidad étnica o cultural, opinión, nivel socioeconómico, condición migratoria, discapacidad, condición de salud, factor genético, filiación, o cualquier otro motivo, será reprimido con pena privativa de libertad no menor de dos ni mayor de tres años, o con prestación de servicios a la comunidad de sesenta a ciento veinte jornadas.

Si el agente actúa en su calidad de servidor civil, o se realiza el hecho mediante actos de violencia física o mental, a través de internet u otro medio análogo, la pena privativa de libertad será no menor de dos ni mayor de cuatro años e inhabilitación conforme a los numerales 1 y 2 del artículo 36 .

A pesar de la amplitud de los motivos de discriminación que se reprime, no se hace ninguna referencia específica a la sanción de conductas discriminatorias en el empleo, las que considero deberían ser objeto de una tipificación específica. 


\section{CONCLUSIONES}

1. La discriminación de la mujer en el trabajo constituye un grave problema de actualidad que afecta no solo la dignidad de la persona, sino también el respeto a los principios y derechos fundamentales en el trabajo, consagrados por la OIT en su Declaración del 18 de junio de 1998.

2. La discriminación es el trato diferenciado que desconoce la igualdad entre las personas a partir de motivos injustificables como son el sexo, la raza, la fe religiosa o la orientación sexual entre otros motivos.

3. La discriminación en el trabajo puede ser directa o indirecta. Será directa cuando las normas legales, las políticas o los actos del empleador afectan directamente la igualdad entre las personas; por otro lado, será indirecta cuando las normas legales, las políticas o actos del empleador son aparentemente inofensivos o neutrales, pero sin justificación alguna sujeta la obtención de un puesto de trabajo o la permanencia en el mismo a requisitos que no son indispensables para el desempeño laboral.

\section{REFERENCIAS}

- Blancas Bustamante, Carlos. Derechos fundamentales de la persona y relación de trabajo. Primera edición. Lima: Fondo Editorial de la Pontificia Universidad Católica del Perú, 2007.

- Jaime Martínez, Héctor Armando. "Los derechos fundamentales de la persona del trabajador". En: Ensayos sobre Derecho del Trabajo y Derecho de la Seguridad Social. Colección de Estudios Jurídicos N 19. Caracas, 2008.

\section{JURISPRUDENCIA}

- STC N 01008-2013-PA/TC del 8 de agosto de 2014, Caso Bayona Vilela, fundamento 3.2.1.

- STC N 01008-2013-PA/TC del 8 de agosto de 2014, Caso Bayona Vilela, fundamento 3.2.2.

- STC N 05652-2007-PA/TC del 06 de noviembre de 2008, Caso Rosa Bethzabé Gambini Vidal, fundamentos 36 y 37.

- STC N 05652-2007-AA, del 06 de noviembre de 2008, caso Rosa Bethzabé Gambini Vidal, fundamentos 34 a 46.

- STC N²01423-2013-AA, del 09 de diciembre de 2015, caso Andrea Celeste Álvarez Villanueva, fundamentos 21 a 24 . 


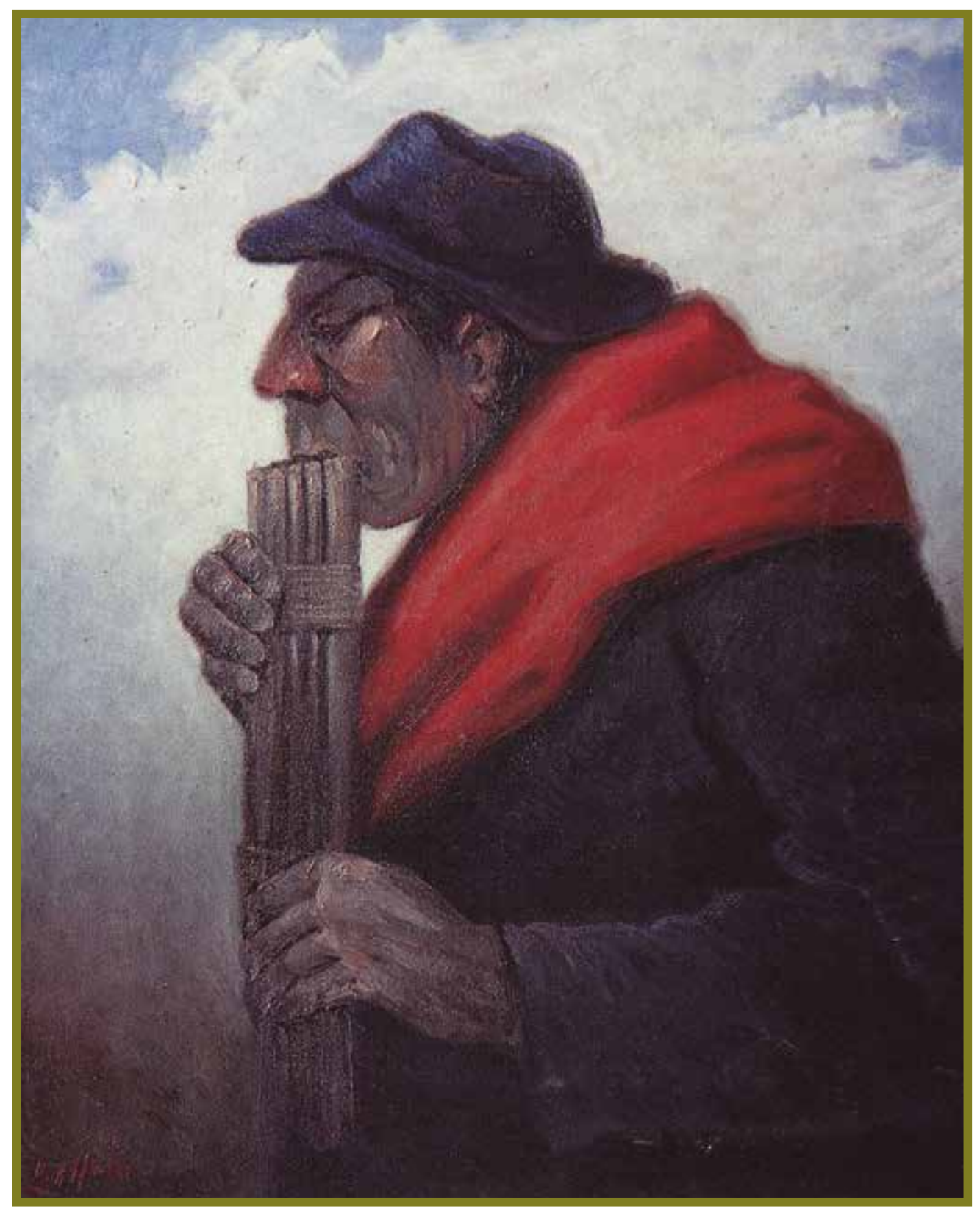

Cusqueño. Óscar Allaín 